\begin{tabular}{|l|l|l|l|l|l|l|}
\hline InterteXto & Uberaba & UFTM & $\begin{array}{l}\text { v. 3 } \\
\text { n. } 2\end{array}$ & p. 49-61 & 2010 - jul. / dez. & ISSN 1981-060 199 \\
\hline
\end{tabular}

\title{
O MITO E O INSÓLITO EM A VIA CRUCIS
}

\section{THE MYTH AND THE UNCOMMON ON "VIA CRUCIS"}

\begin{abstract}
Aline Brustello Pereira ${ }^{1}$
Resumo: Neste trabalho far-se-á primeiramente uma abordagem sobre a conceituação de mito, através de uma abordagem histórica. Posteriormente, far-se-á uma assimilação do mito com seu desenvolvimento literário. Em seguida, arrolará uma análise do conto Via crucis de Clarice Lispector, com o objetivo de delinear os percursos mitológicos do conto, de sua causalidade insólito-fantástico.
\end{abstract}

Palavras-chaves: Mito; Via crucis; Insólito; Fantástico.

Abstract: In this work first become a boarding on the myth conceptualization, through a history. Later, an assimilation of the myth with its literary development. After that, an analysis of the story "Via crucis" from Clarice Lispector will enroll, with the objective to delineate the myths passages of the story, of its uncommon-fantastic.

Key-words: Myth; Via crucis; Uncommon; Fantastic.

\section{Introdução}

"A via crucis não é um descaminho, é a passagem única, não se chega senão através dela e com ela" (LISPECTOR, 1998)

Escrito em 1974, por "liberdade para escrever o que bem quisesse", o livro A Via crucis do Corpo escrito por Clarice Lispector é precedido por uma explicação da autora: "se há indecências nas histórias a culpa não é minha". Como toda a sua obra, os contos que compõem o livro não fogem às questões filosófico-existencialistas. Desta vez, porém, Clarice centra-se na mulher, colocando-a como condutora de todos os contos, abrindo uma fresta no cárcere social que a mantém.

O conto Via crucis, que nomeia metade do título da obra, (junto a outro conto que possui o nome de Corpo) traz Maria das Dores, mulher, que mesmo casada mantinha-se virgem, mas engravida. Nesta feita, a partir de um conflito

\footnotetext{
${ }^{1}$ Mestranda - Universidade Federal de Uberlândia - UFU. alinebrustello@gmail.com
} 


\begin{tabular}{|l|l|l|l|l|l|l|}
\hline InterteXto & Uberaba & UFTM & $\begin{array}{l}\text { v. 3 } \\
\text { n. } 2\end{array}$ & p. 49-61 & 2010 - jul. / dez. & ISSN 1981-060 50 \\
\hline
\end{tabular}

existencial, (todos passam pala via crucis (?)) Clarice narra um acontecimento mitológico, tentando dar explicação, ao que a razão humana, tem por inexplicável.

Pensando o mítico nessa via, pode-se conceituar Via crucis como um conto de caráter fantástico. Quando Maria das Dores conta ao seu marido sobre a gravidez, o mesmo se diz José. A partir disso, há o deslocamento do casal rumo a uma fazenda no interior de Minas Gerais, fazendo a incorporação total pelo casal do mito da concepção de Nossa Senhora.

Como fica claro com as mudanças de lugares efetuada pelo casal, personagens principais do conto, não obstante a todo elemento imaginário, é o espaço que possui a função de fazer surgir e acontecer todo enredo mítico, por isso o espaço será tema central para este artigo. Portanto, com base em todo estudo do mito, explicitar-se-á o espaço como função central do desenvolvimento do conto.

Nesse sentindo, em um primeiro momento far-se-á alusão ao elemento mito, com um percurso histórico, com o intuito de se compreender melhor o que é um mito. Por conseguinte, haverá uma assimilação do mitológico com a literatura. E por final a análise do conto Via crucis de Clarice Lispector, explicitando o espaço como elemento formador do insólito.

\section{Percurso histórico do mito e o mito na literatura}

Nas sociedades primitivas, o mito era tido como uma historia verdadeira de caráter sagrado, desempenhando função dentro do plano social. Nesse sentindo, o mito fala, nesse período, do que realmente ocorreu, de coisas reais que vieram à existência por obra do sagrado, servindo como modelo exemplar de todas as atividades humanas.

O mito dessa sociedade se opunha ao que se dizia profano, ou histórias falsas, sendo o mito o que era verdadeiro, desse modo, para o homem primitivo, conhecer o mito era conhecer a verdade, aprendendo a origem das coisas. A palavra, nessa via, é um meio de potência, que se sobrepõe até 


\begin{tabular}{|l|l|l|l|l|l|l|}
\hline InterteXto & Uberaba & UFTM & $\begin{array}{l}\text { v. 3 } \\
\text { n. } 2\end{array}$ & p. 49-61 & 2010 - jul. / dez. & ISSN 1981-060 51 \\
\hline
\end{tabular}

mesmo ao poder dos deuses. Tanto a linguagem como 0 mito possuem 0 poder metafórico como meio de concepção mental. Ambos (mito e linguagem) estão em correlação indissolúvel, possuindo a mesma informação simbólica. A separação gradual entre mito e linguagem acontece quando o homem começa a desenvolver o logus.

Foi com o surgimento da escrita que o mito ganhou uma nova interpretação. Com apenas o oral, o mytho não era separado do logus, isto é, não havia separação entre criação e razão. Com a escrita, houve um acirramento do conceitual, bem como seu ordenamento, com isso ocorreu a separação da palavra falada e da palavra escrita. Com a palavra falada o narrador busca encantar o ouvinte, com a palavra escrita busca-se convencer o leitor da verdade veiculada. Estabeleceu-se a distinção entre mythos, sendo o fascinante, o fabuloso, e logus, o verdadeiro, o inteligível.

À medida que o pensamento lógico-científico avança, o mito se dissolve da linguagem e centra-se apenas em expressões, como por exemplo, a artística. Com o passar do tempo a narrativa fundadora mítica assume outras funções, como função de legitimação histórica.

Com Freud, os estudos míticos tomaram nova ênfase. Através da análise do inconsciente humano, o psicanalista, conseguiu verificar como as estruturas simbólicas estavam resguardadas na mente dos seres humanos. Carl Jung foi além quando propôs a existência de um imaginário coletivo, sendo estas de caráter universal e inato, pois segundo ele, todas as culturas desenvolveram narrativas míticas, havendo nelas imagens recorrentes. Portanto, nas imagens e nos símbolos pode-se estar condensado o pensamento mítico.

Diante disso, pode-se entender o conceito de mito como forma literária, visto que esta está amplamente ligada com a mitologia. Pode-se entender o mito como um acontecimento que a razão humana não pode compreender. Do mítico sempre advém um conflito existencial. Percebe-se, através dessa conceituação, que o mito na literatura filia-se ao mito como forma primitiva, 


\begin{tabular}{|l|l|l|l|l|l|l|}
\hline InterteXto & Uberaba & UFTM & $\begin{array}{l}\text { v. 3 } \\
\text { n. } 2\end{array}$ & p. 49-61 & 2010 - jul. / dez. & ISSN 1981-060 52 \\
\hline
\end{tabular}

uma vez que nessa época o mito era visto como determinante da existência e da condição humana.

Pode-ser perceber a utilização da mitologia na literatura de diversas formas. Na Idade Média, por exemplo, abriu-se mão do paganismo a favor do mito cristão. No Renascimento o mito transforma-se em metaforicidade poética. É no século XVII que surgem tipos de comportamentos universais, tornando-se conhecidos na literatura, como Hamlet e Dom Quixote. Já no século XVIII surge o mito burguês e a identificação da natureza humana. No século $X X$, a literatura oscila entre o misticismo e o fantástico, com tons de ironia e humor, é nesse momento também que, apoiada na psicanálise, desenvolve-se a interiorização da ação principal, o monólogo interior e o fluxo de consciência.

De acordo com Mielietinski, oposição entre psicologia e história, sincretismo e pluralismo mitológico, repetição cíclica de mitos para representar arquétipos universais, papeis de fácil substituição, são elementos recorrentes de narrativas mitológicas. Todos esses elementos são passíveis de verificação em narrativas fantásticas.

O fantástico se instaura na linha tênue da hesitação. Quando há um acontecimento que pode ser explicado pelas leis imaginárias temos 0 maravilhoso. Quando há um acontecimento tratado como uma explicação possível do real, trata-se do estranho.

Considerando os temas do fantástico, Todorov se aproxima dos postulados da psicanálise, dividindo os temas em dois grandes grupos: os temas do "eu" que concernem essencialmente à estruturação da relação entre o homem e o mundo; e os temas do "tu" que tratam da relação do homem com seu desejo e, por isto mesmo, com seu inconsciente. Após uma análise temática de algumas obras do gênero fantástico, Todorov conclui que a função do sobrenatural é subtrair o texto à ação da lei e com isto mesmo transgredi-la. O fantástico teria a função de possibilitar a livre expressão de temas considerados tabus, os quais aparecem transvestidos numa roupagem sobrenatural. Essa espécie de transvestimento torna-se desnecessária com o surgimento da psicanálise, pois os temas da literatura fantástica tornaram-se os mesmos das 


\begin{tabular}{|l|l|l|l|l|l|l|}
\hline InterteXto & Uberaba & UFTM & $\begin{array}{l}\text { v. 3 } \\
\text { n. } 2\end{array}$ & p. 49-61 & 2010 - jul. / dez. & ISSN 1981-060 53 \\
\hline
\end{tabular}

investigações psicológicas, denotando, assim, a relação da literatura fantástica com as imagens submersas no inconsciente humano." (MONFARDINI, 2005, p. 58)

Partir-se-á para a análise do conto Via crucis de Clarice Lispector à luz da conceituação mitológica por hora arrolada.

\section{A via crucis e as significações mitológicas}

A princípio, podem-se perceber três ênfases no conto Via crucis ao que se refere ao mito retratado: a sexualidade de forma transgressiva, a semântica dos nomes, a glutonaria/a ironia.

\subsection{A sexualidade}

Contrariando os princípios da concepção normal, em que um novo indivíduo só é gerado pela relação sexual masculino/feminino, Maria das Dores (nome, aliás, bastante sugestivo para a temática posta ali em questão), tal qual a Virgem Maria, se encontra grávida de um menino. 0 que pensamos ser, efetivamente, inconcebível ocorre. Vê-se, pois, que Clarice lança mão de uma ironia para criticar os efeitos que a moral cristã provocou no pensamento ocidental quando ligou o sexo ao pecado. Constrói-se, assim, uma narrativa em que Maria das Dores, segue o mesmo percurso e o mesmo ritual da Virgem Maria quando concebeu Jesus Cristo.

Conforme Bataille (1980), o mundo da religião é uma tensão trágica entre o profano e o sagrado. O pensamento cristão desconhece e ignora a tensão da atividade sexual. Por isso condena a sexualidade. Na esfera humana, a atividade sexual é essencialmente uma transgressão. "A essência do erotismo reside na inextrincável associação entre o prazer sexual e o proibido. Nunca, humanamente, a proibição surge sem a revelação do prazer e nunca o prazer surge sem o sentimento de proibição." (Bataille, 1980, p.96)

De acordo com o autor, a moral cristã, ao investir contra um movimento 


\begin{tabular}{|l|l|l|l|l|l|l|}
\hline InterteXto & Uberaba & UFTM & $\begin{array}{l}\text { v. 3 } \\
\text { n. } 2\end{array}$ & p. 49-61 & 2010 - jul. / dez. & ISSN 1981-060 54 \\
\hline
\end{tabular}

natural que é a atividade sexual tornou-se, por assim dizer, a menos pura das religiões, porque é mediatizada pelo mundo do trabalho, pois condena todas as formas de erotismo, inclusive o sagrado. O pensamento cristão orienta que o homem deve realizar sacrifícios para alcançar os méritos do mundo sagrado. Para entrar no reino do divino é preciso abdicar-se dos prazeres carnais. Nesse sentido, ceder às tentações da carne é sujeitar-se a perder um lugar no paraíso. Na interpretação que se faz da gênese bíblica o casal de humanos separa-se de Deus ao descobrir seus corpos nus. Separar-se de Deus é descobrir os efeitos de não possuir atributos divinos: eternidade, infinitude, incorporeidade, auto-suficiência e plenitude. "Ora, pelo sexo, os humanos não somente reafirmam sem cessar que são corpóreos e carentes, mas também não cessam de reproduzir seres finitos. O sexo é o mal porque é a perpetuação da finitude." (BATAILLE, 1991, p.87). Pelo sexo o homem descobre a sua essência, a sua finitude, por sua vez, é a queda.

A queda o distancia para sempre de Deus, é o sentimento de um rebaixamento real e do qual a descoberta do sexo como vergonha e dor futura é o momento privilegiado. Com o sexo os humanos descobrem o que é possuir corpo. Corporeidade significa carência [...] desejo, limite e mortalidade. (BATAILLE 1991, p. 86)

Se o corpo é, naturalmente, morada do desejo e este se encontra, encravado na carne, tem de ser, então, alimentado. Não havendo, portanto, possibilidade, por vias normais, de fugir às tentações. A não ser por obra do Divino, como ocorreu com a Virgem Maria. Portanto, a virgindade, a negação do desejo, imposta pela moral cristã, principalmente à mulher, é um sacrifício, uma via-crucis no entender clariceano. Há, portanto, ironia na alusão bíblica clariceana. Os dados sugerem que Maria das Dores dissimula uma situação de disfarce de um filho gerado fora do casamento. A menstruação estava atrasada foi isso que a levou à ginecologista. Ela era virgem do casamento, do marido, pois este era impotente, o que nos leva a pensar num possível relacionamento dessa mulher com outro homem. Chegando a casa contou 


\begin{tabular}{|l|l|l|l|l|l|l|}
\hline InterteXto & Uberaba & UFTM & $\begin{array}{l}\text { v. 3 } \\
\text { n. } 2\end{array}$ & p. 49-61 & 2010 - jul. / dez. & ISSN 1981-060 55 \\
\hline
\end{tabular}

ao marido o que acontecia.

O homem se assustou: - Então eu sou S. José? - é foi a resposta lacônica. [...] A uma amiga mais íntima Maria das Dores contou a história abismante. A amiga também se assustou: Maria das Dores, mas que destino privilegiado você tem! - privilegiado, sim, suspirou Maria das Dores. Mas o que posso fazer para que meu filho não siga a via crucis? (LISPECTOR, 1998, p.30)

Observa-se, pois, que o artifício da ironia é o que sobressai nessa narrativa. O sacrifício imposto pela sociedade, fazendo com que o sujeito ignore seus desejos, os desejos que lhe são inatos. Ao se ver naquela situação, Maria das Dores, recorre à Virgem Maria. José, por sua vez, tem de aceitar, pois é melhor aceitar esse fato que confessar sua "incompetência". A personagem Maria das Dores do conto a Via crucis encontra no sacrifício de Maria um "modelo" e uma saída para a interdição imposta pelas convenções sociais que prevê uma norma de comportamento, que impede a manifestação do desejo carnal, e interdita o sexo, principalmente às mulheres, regulando-os e reprimindo-os; delimitando e cristalizando papéis e imagens que, na verdade, alienam e deslocam o desejo.

\subsection{A semântica dos nomes}

Os nomes dos personagens, aprofunda a similitude com o mito, num esforço de os personagens se identificarem com as figuras bíblicas: o filho será "Jesus", o marido passa a ser nomeado "São José", apenas Maria continua "das Dores".

A partir de todas as alusões aos fatos bíblicos, o leitor pode se posicionar diante de uma inquietação: a expectativa de o filho seguir ou não a via crucis tal como Cristo e as próprias personagens demonstram essa inquietação e procedem a uma mudança no nome da criança, que passa a se chamar Emmanuel. É importante observarmos o jogo semântico 


\begin{tabular}{|l|l|l|l|l|l|l|}
\hline InterteXto & Uberaba & UFTM & $\begin{array}{l}\text { v. 3 } \\
\text { n. } 2\end{array}$ & p. 49-61 & 2010 - jul. / dez. & ISSN 1981-060 5q \\
\hline
\end{tabular}

utilizado por Clarice, que atribui às suas personagens nomes cuja importância apreende o leitor no curso da narrativa, a exploração do poder agregado e atribuído aos nomes, envolvendo-se com o desenrolar da vida dos personagens.

Virgem Maria, santidade de Maria das Dores, mãe de Jesus, é cultuada pela igreja católica com diversos nomes. Conhecida também como Nossa Senhora da Piedade, Nossa Senhora da Soledade, Nossa Senhora das Angústias, Nossa Senhora das Lágrimas, Nossa Senhora das Sete Dores, Nossa Senhora do Calvário, Nossa Senhora do Pranto. Todos esses nomes para identificar a mãe de Jesus, que passara com ele todos os pergaminhos de sua vida. Esses nomes ainda estão ligados às ditas "Sete Dores de Maria", visto que como sua mãe, esta passou por todos seus sofrimentos. A contar, primeiramente, pelas profecias de Simeão, homem sábio e justo que previu que Jesus seria motivo de contradição.

Quando se completaram os dias para a purificação deles segundo a lei de Moisés, levaram o menino a Jerusalém a fim de apresentá-lo ao Senhor... e Havia em Jerusalém um homem chamado Simeão que era justo e piedoso... Simeão os abençoou e disse a Maria, sua mãe: Eis que este menino está destinado a ser ocasião de queda e elevação de muitos em Israel e sinal de contradição. Quanto a ti, uma espada te transpassará a alma (Lucas; 2,22. 25a. 34-35).

A segunda dor de Maria foi a partida da família sagrada em fuga para 0 Egito, uma vez que o Rei Herodes, sentindo seu reinado ameaçado pelos judeus decide mandar matar todas as crianças com menos de dois anos de Belém. Eis então que um anjo acorda José e manda-o para o Egito para proteger seu filho.

O casal Maria e José ainda passou pela aflição do desaparecimento do menino Jesus. Ele sumiu durante três dias e fora encontrado no templo. Essa foi a terceira dor de Maria. 


\begin{tabular}{|l|l|l|l|l|l|l|}
\hline InterteXto & Uberaba & UFTM & $\begin{array}{l}\text { v. 3 } \\
\text { n. } 2\end{array}$ & p. 49-61 & 2010 - jul. / dez. & ISSN 1981-060 57 \\
\hline
\end{tabular}

A quarta dor de Maria, e a mais conhecida, é seu encontro com Jesus na ida ao Calvário. Como também sua quinta dor, Maria observando Jesus ser crucificado na cruz. A sexta dor, Maria recebe o corpo de seu filho. E a sétima, ela vê seu filho ser levado ao santo sepulcro. Por tudo isso, a imagem de Maria é relacionada muitas vezes à espada transpassada, como Simeão

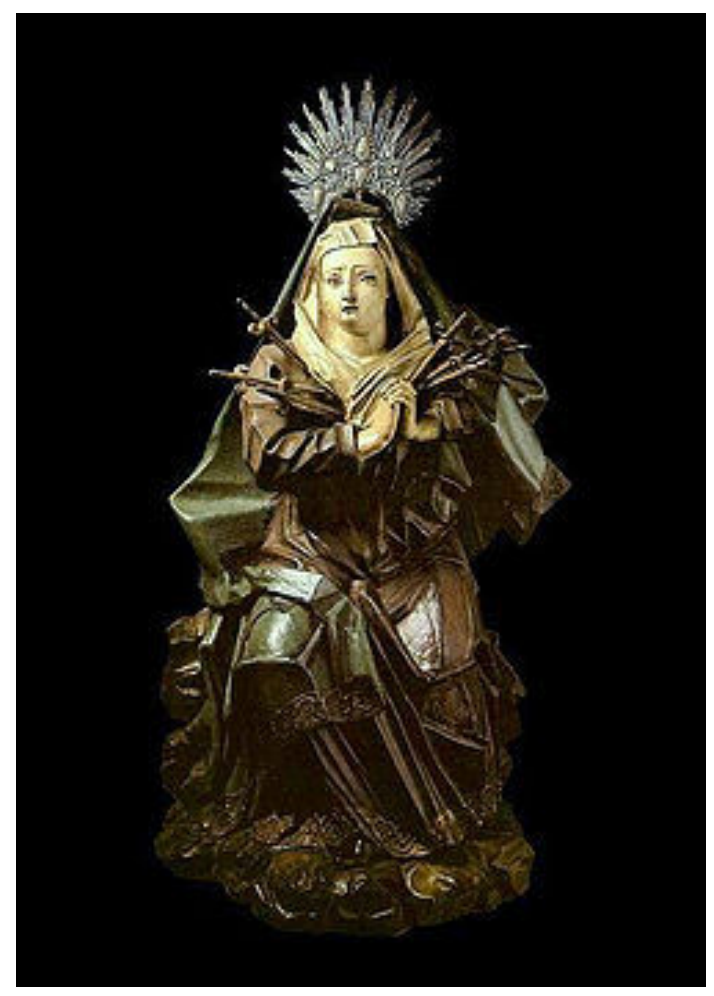

previu.

(Maria, em escultura de aleijadinho. Observa-se as sete espadas incrustadas a ela)

José nasceu em Belém da Judéia no século I a. C. Alguns historiadores dizem que ele era da tribo de Judá e descendente da Davi de Israel. É por José, inclusive, que é atestada a Jesus a ascendência até Davi e Abrahão. Porém, o texto bíblico deixa claro que Jesus não era filho biológico de José, pois Maria engravidou antes de eles coabitarem, e um anjo pede a ele em sonho que resguarde a criança visto que ela era filha do Espírito Santo.

O nome Emmanuel por sua vez é bem simbólico no conto. De origem 


\begin{tabular}{|l|l|l|l|l|l|l|}
\hline InterteXto & Uberaba & UFTM & $\begin{array}{l}\text { v. 3 } \\
\text { n. } 2\end{array}$ & p. 49-61 & 2010 - jul. / dez. & ISSN 1981-060 58 \\
\hline
\end{tabular}

hebraica, Emanuel foi o primeiro nome dado ao filho de Maria e José pelo profeta Isaías. Só mais tarde, então, é que o menino seria identificado como Jesus. O significado ainda pode ser explicitado pelo fato de Clarice tê-lo colocado com duas letras "m" ao meio. Essas letras são as iniciais do nome da mãe do menino, Maria, não há as letras do pai, José.

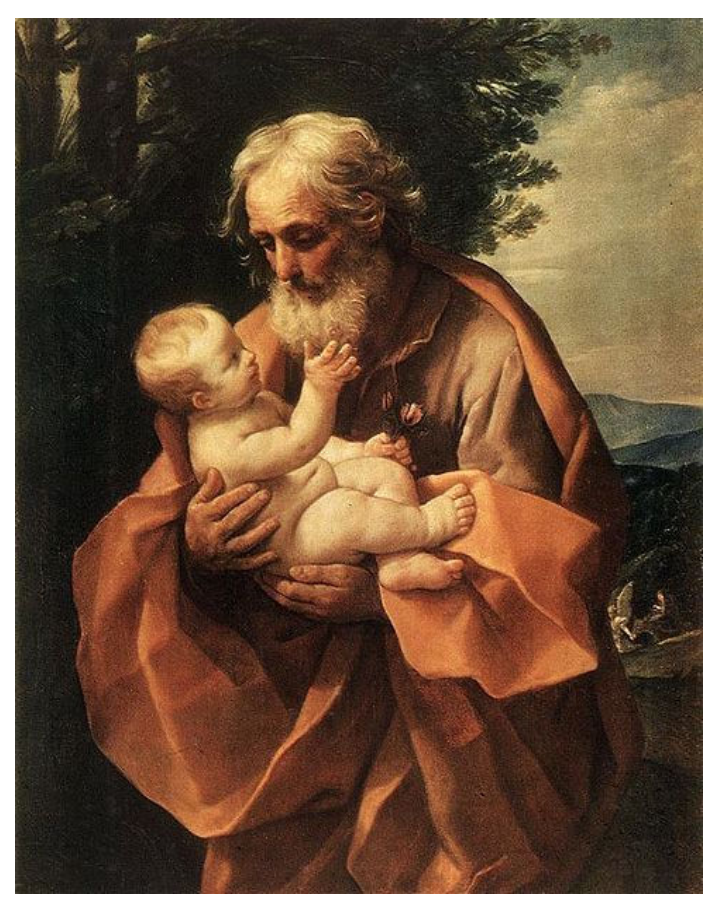

(José com Emmanuel às mãos)

Haja vista os significados desses nomes, percebe-se que ao mesmo tempo em que os nomes inserem a história dentro do mito bíblico, eles se tornam irônicos e criam novos sentidos na história. Colocam dúvida sobre a paternidade do pai da criança, como também se realmente, no conto, Maria era ou não virgem.

\subsection{Glutonaria}

Não bastasse as ironias elencadas acima, Clarice, em sua transposição mitológica à vida cotidiana, traz ainda mais ironias: a 


\begin{tabular}{|l|l|l|l|l|l|l|}
\hline InterteXto & Uberaba & UFTM & $\begin{array}{l}\text { v. 3 } \\
\text { n. } 2\end{array}$ & p. 49-61 & 2010 - jul. / dez. & ISSN 1981-060 59 \\
\hline
\end{tabular}

espiritualidade elevada, expressa na oração e na meditação, aparece ligada aos exageros da comida. Assim, Maria das Dores "tomava grosso leite branco, com o terço na mão", São José meditava na montanha, conforme o bíblico, e logo após todos se reuniam, colocados na narrativa com o mesmo respeito e deferência da oração, e todos "comiam danadamente".

Os motivos da comida ou da glutonaria, ausentes no mito bíblico original, ao mesmo tempo em que dão ao conto um toque irônico, contribuem para retirar da narrativa mítica o traço de transcendência, lançando a história na esfera humana, equivalendo as necessidades espirituais às necessidades fisiológicas, situando a problemática abordada no conto no âmbito da existência humana terrena.

\section{Considerações finais}

A semântica dos nomes e a glutonaria dão um caráter irônico ao conto. É exatamente essa ironia que cria a expectativa, o questionamento. Emmanuel, com dois "m", tem a marca do nome de sua mãe em seu nome, por isso mão seria ele apenas de Maria (com outro homem?). Maria, que continuou das dores, não sugere a dificuldade dela em mentir ao seu marido? E o pecado da gula, colocado tão insistentemente, não reforça a colocação das personagens como seres reais e não bíblicos?

Depois de visualizados esses apontamentos, pode-se perceber que o texto clariceano, conto Via crucis, permanece na hesitação da colocação do insólito. Não se sabe ao certo se Maria das Dores era ou não era virgem, e se era ou não a criação de uma "fantástica" gravidez. Não há uma explicação, permanece a hesitação no leitor, por isso, o conto pode ser visto como de caráter amplamente fantástico.

O que pode ficar claro na leitura do conto é que Clarice Lispector faz uma reescritura do mito bíblico. Ainda que permaneça na hesitação, o conto nos faz pensar sobre a veracidade da história da Virgem Maria contada pela 


\begin{tabular}{|l|l|l|l|l|l|l|}
\hline InterteXto & Uberaba & UFTM & $\begin{array}{l}\text { v. 3 } \\
\text { n. } 2\end{array}$ & p. 49-61 & 2010 - jul. / dez. & ISSN 1981-060 50 \\
\hline
\end{tabular}

moral cristã. Com isso, surgem novos sentidos a partir do conto a serem repensados, quem sabe, talvez, algum dia revistos.

O conto que dá título ao livro "Via crucis" exibe a estória de uma personagem que fica grávida sem ter tido relações com o marido. A criança gerada não foi resultado de relação sexual; não foi produto da cessão aos desejos do corpo. A futura mãe diz que não quer que o futuro filho passe pela via crucis do corpo: "Mas o que posso fazer para que meu filho não siga a via crucis?”. (LISPECTOR, 1998, p.30) Em um dado momento ela começa a sentir enjôos e pensa: "começou a via crucis do meu sagrado filho". No fim do conto a questão: "Não se sabe se essa criança teve que passar pela via crucis. Todos passam" (1998 p.33) Mas o que seria essa via crucis? A via crucis do corpo é o nome que dá título ao livro. E é sobre esse corpo que o livro trata.

É importante mencionar que a escritora já antecipara essa verdade no fechamento de seu segundo livro: $A$ paixão segundo $G H$ quando dissera: "A via-crucis não é um descaminho, é a passagem única, não se chega senão através dela e com ela." (1998, p.178). Essa antecipação, a nosso ver, aponta o caminho do sacrifício que é o estar no mundo. Logo, pela via crucis todos têm de passar, pois todos somos seres viventes e estamos no mundo. O mundo que nos rodeia nos atinge de todas as formas, fisicamente, emocionalmente. O corpo sofre pelos ferimentos físicos e também pelos ferimentos da alma. É nele, no corpo, que reside, que se deposita os desejos, os anseios, as perdas, as dores, a felicidade, o amor, o ódio.

\section{Referências}

BATAILLE, Georges. A literatura e o mal. Tradução de Antonio Borges Coelho. Paris: Ulisseia, 1957.

O erotismo. Tradução Antonio Carlos Viana. 2 ed. 


\begin{tabular}{|l|l|l|l|l|l|l|}
\hline InterteXto & Uberaba & UFTM & $\begin{array}{l}\text { v. 3 } \\
\text { n. 2 }\end{array}$ & p. 49-61 & 2010 - jul. / dez. & ISSN 1981-060 11 \\
\hline
\end{tabular}

Lisboa: Moraes Editores, 1991

LISPECTOR, Clarice. A via crucis do corpo. Rio de Janeiro: Rocco, 1998. A Paixão Segundo GH. Rio de Janeiro: Rocco, 1998.

Lucas. Português. In: Bíblia sagrada. Tradução de Padre Antônio Pereira de Figueredo. Rio de Janeiro: Encyclopedia Britânnica, 1980. p. 389-412. Edição Ecumênica. Bíblia. A.T.

MONFARDINI, Adriana. O Mito e a Literatura. In: Terra Roxa e Outras

Terras: Revista de Estudos Literários - UFSM. Volume 5, 2005. PP. 50 a 61. 